\title{
Time-dependent damage caused by enhanced greenhouse conditions
}

\author{
X.Q. Ding ${ }^{1}$, G.R. Willgoose ${ }^{2}$, M.G. Stewart ${ }^{3}$ \\ ${ }^{1}$ School of Engineering, The University of Newcastle, Callaghan New South Wales 2308, Australia, \\ ph: +61 2 49215816, email: Xiaoqian.Ding@studentmail.newcastle.edu.au \\ ${ }^{2}$ Director, Centre for Climate Impact Management (C2IM), Head of Discipline Discipline of Civil Surveying \\ and Environmental Engineering, The University of Newcastle, Callaghan New South Wales 2308, Australia \\ ph:+612 49216050, email: garry.willgoose@newcastle.edu.au \\ ${ }^{3}$ Australian Research Council Professorial Fellow; Director, Centre of Infrastructure Performance and Reli- \\ ability, The University of Newcastle, Callaghan New South Wales 2308, Australia \\ ph: +61 2 4921607, email: mark.stewart@newcastle.edu.au
}

\begin{abstract}
Damage to infrastructure caused by anthropogenic climate change can cause dramatic economic loss and social disruption. According to the Intergovernmental Panel on Climate Change, climate change may cause an increase in the intensity of droughts, the frequency of floods, and increasing coastal vulnerability to tropical cyclones, storm surges and sea-level rise. This paper uses the stochastic technique Monte Carlo technique to explore the time-dependent damage due to climate change, considering the hazard as a stochastic variable. Three different time periods were explored: 2010-2035, 2010-2050 and 2010-2100. The analysis investigated no climate change and with climate change scenarios that affect the probabilistic model of hazard occurrence, and vulnerability functions that represent the potential damage for a given hazard. The probabilistic model and vulnerability models used in this study are relatively simple, but they can help to generate a framework of the time-dependent climate change damage and understand its economic behaviour. Parametric studies are heavily used in this study to explore a range of possible conclusions. The sensitivity of the change of parameters such as threshold $h_{T}$, discount rate $r$, and time $T$ are considered. The results are given in terms of mean cumulative annual loss. The discount rate was found to be a key parameter affecting cumulative damage prediction. Since damage often only occurs once a threshold level of hazard has occurred (such as a flood level exceeding the floor level of a house), then the influence of this threshold value on damage is significant. Damage/impact models utilising probabilistic hazard were used to verify the robustness of results. Results are very sensitive to threshold. Time-dependent predictions of damage can help decisionmakers assess the impact of climate change and the economic viability of climate change adaptation strategies.
\end{abstract}

Keywords: Time-dependent Damage, Climate Change, Discount Rate, Threshold 


\section{INTRODUCTION}

Climate change continues to figure prominently on the environmental policy agenda, both nationally and internationally (Cleugh et al. 2011). Anthropogenic climate change can cause large economic and environment loss to infrastructure. Potential consequences of climate change include an increased risk of floods and droughts, losses of biodiversity, threats to human health, and damage to economic sectors such as forestry, agriculture, tourism and the insurance industry (IPCC, 2007). For example, Hurricane Andrew in 1992 caused $\$ 30$ billion in damage (Stewart 2003). Cyclone Larry in 2006 damaged about 20\% of housing and caused over $\$ 1$ billion in damage (Ginger et al. 2007). The potentially significant economic losses that may be caused by climate change requires policy makers to generate appropriate cost-effective adaptation strategies, which can mitigate the damage and reduce the vulnerability of society to climate change. However, the highly uncertain nature of climate change and the lack of reliable knowledge of the vulnerability of infrastructure to climate change make the determination of adaptation strategies challenging. Estimates of damage related to climate change can make an important contribution to decision making regarding response through adaptation.

Many engineers and economists devote themselves to exploring the impacts caused by enhanced climate change. Some of them focus on a specific issue caused by climate change. For example, Li and Stewart (2011) have proposed a risk-based analysis for evaluating the potential cyclone damage risks to residential construction due to climate change by evaluating the cost effectiveness of different adaptation strategies. Pinelli et al. (2009) has addressed methods for evaluating the economic feasibility of hurricane mitigation measures for residential buildings in Florida. Khanduri and Morrow (2003) has discussed the vulnerability of buildings to windstorms and developed vulnerability functions for windstorm loss estimation. Economist Stern highlights the global economic impacts caused by climate change. The Stern Review (2006) has examined the evidence on the economic impacts of climate change, investigated the economics of stabilizing greenhouse gas concentrations in the atmosphere and considered the policy response for mitigation and adaptation. Garnaut (2008) has examined the impacts of climate change on the Australian economy as well as the costs of adaptation and mitigation.

In the absence of research on infrastructure damage behaviour, the paper will develop a methodology to explore the time-dependent damage caused by human-enhanced climate change. The focus of this paper is to develop a framework of climate change impacts, which can be applied to real case studies for future research work, such as flooding hazards to infrastructure caused by anthropogenic-enhanced climate change. The effect of damage threshold, discount rate and time period will be considered. Results will be given in terms of mean cumulative damage loss over time.

\section{PROBABILISTIC HAZARD MODEL}

The hazard (e.g. floods, extreme wind) is modelled as a log-normal probability distribution $f(h, t)$, where $h$ is the hazard, and $t$ is time. Since there is a high uncertainty on how climate change will affect the occurrence of hazards, both linear and nonlinear time-dependent increase of hazards are considered. In our case, the mean hazard value $\mu_{h}$ is time dependent, $\mu_{h}(t)$, which is assumed linearly (2) and nonlinearly (3) increasing with time from $a$ to $b$ as shown in Fig.1. The time-dependent probability density function of the log-normal distribution for hazard occurrence is

Probability Function: $\quad f(h, t)=\frac{1}{h \sigma \sqrt{2 \pi}} e^{-\frac{\left(\ln h-\mu_{h}(t)\right)^{2}}{2 \sigma^{2}}} ; h>0$

Linear: $\quad \mu_{h}(t)=a+(b-a) \frac{t}{T} ; b \geq a \quad$ (2) Nonlinear: $\quad \mu_{h}(t)=a\left(\frac{b}{a}\right)^{\frac{t}{T}} ; b \geq a$

where $T$ is the end time in months. In this study, three different time periods: 2010-2035, 2010-2050 and 2010-2100 are considered. The exploration of the three different time periods represents short-term and longterm impacts of climate change. Parameters $a$ and $b$ are site specific, denoting the intensity of the hazard at the end of $T$ years. If there is no climate change, the $a$ and $b$ are equal to 1 . In the climate change scenario, $b$ increases from 1 to 2 of the end of time period $T$. This is because of the uncertainty of the potential impacts due to climate change. The uncertainty of global warming means that wind speed can increase from 5 to $25 \%$ within 50 years ( $\mathrm{Li}$ and Stewart 2011), which indicates that $b$ can approach 1.25 in 50 years. Parameter $\sigma$ is site specific but assumed to be 0.5 in this study.

\section{VULNERABILITY FUNCTION}

A vulnerability model defines the damage due to occurrence of a hazard. The vulnerability model used in this study is 


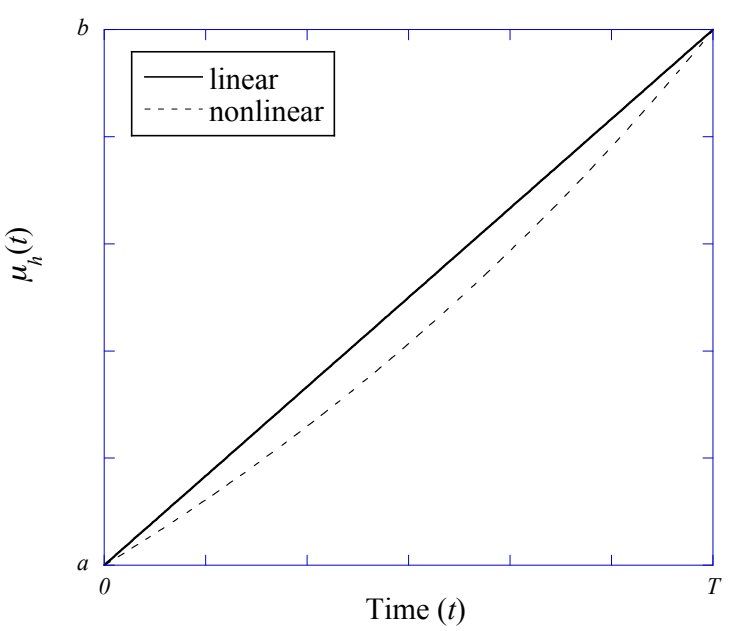

Fig,1. Time-dependent increase in mean hazard value

$$
\begin{aligned}
& V(h)=m h+n ; \quad h>h_{T} \\
& V(h)=0 ; \quad h \leq h_{T}
\end{aligned}
$$

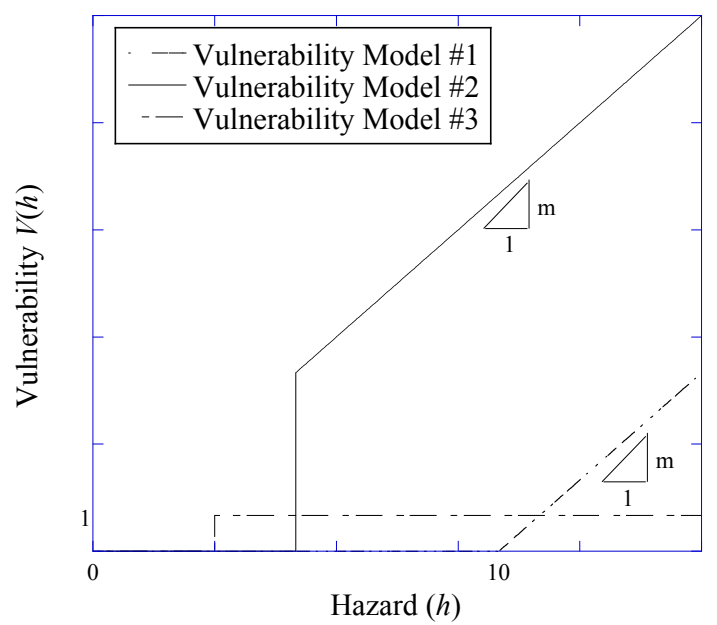

Fig.2. Three Different Vulnerability Models

where parameters $m$ and $n$ are site specific, and parameter $h_{T}$ represents a threshold value of climate impact below which there is nil damage. This study focuses on obtaining general knowledge concerning the time dependent characteristic of climate change damage. Three different vulnerability models are explored in this study as shown in Fig.2. Vulnerability model \#1 is used in no climate change scenario, where parameters $m$ and $n$ are set at 0 and 1 respectively. The other two vulnerability models are adopted in climate change scenarios. Vulnerability model \#2 assumes that the damage caused by climate change is equal to the severity of climate change by setting parameters $m$ and $n$ at 1 and 0 . Vulnerability model \#3 aims at assessing the sensitivity of the parameter $n$ by giving $n=-10$.

\section{CUMULATIVE DAMAGES OVER TIME}

The damage caused by a climate change induced hazard is determined by convolving the vulnerability and hazard functions. The damage $D(t)$ in month $t$ caused by climate change can be calculated as

$$
D(t)=\int V(h) f(h, t) d h
$$

where $V(h)$ is vulnerability function defined in Eq.(4) and is $f(h, t)$ time-dependent probability density function for climate change hazard in Eq.(1). The cumulative damage $C D$ is:

$$
C D(t)=\sum_{t=1}^{T} \frac{D(t)}{(1+r)^{t}}
$$

where $r$ is the monthly discount rate. The term $1 /(1+r)^{t}$ is the discount factor, by which future values are multiplied to convert them to present values (Ackerman et al. 2006).

\section{RESULTS}

\subsection{No Climate Change Scenario}

In the no climate change case, parameters $a$ and $b$ in equation (2) are both set at 1 , so that neither climate mean nor variability actually change, neglecting the influence of the rate of climate change. Vulnerability model \#1 as shown in Fig.2 is used herein. In order to make the results comparable, threshold $h_{T}$ is set at a constant value 6 to explore the consequences of different discount rates. Threshold is a level at which climate change hazard would happen. For example, for flood hazard, the threshold $h_{T}$ can represent for the floor level of a house. When a flood level exceeding the threshold $h_{T}$, damage occurs. Fig. 3 represents the mean cumulative damage under different monthly discount rates, from low to high, $r=0.0 \%, r=0.2 \%, r=0.4 \%, r=0.6 \%$ and $r=0.8 \%$ respectively. The corresponding annual discount rates are $0.0 \%, 2.43 \%, 4.91 \%, 7.44 \%$ and $10.03 \%$ respectively. For the discount rate $r=0.0 \%$, the damage increases linearly. When the discount rate $r$ exceeds zero, the mean cumulative damage increases faster in short-term. With the increasing of discount rate, it reduces eventually. Climate change adaptation strategies can reduce the vulnerability but will require significant expense. Adaptation will cost tens of billions of dollars a year in developing countries alone, and will put still further pressure on already scarce resources (Stern, 2006). According to the findings in Fig.3, the 


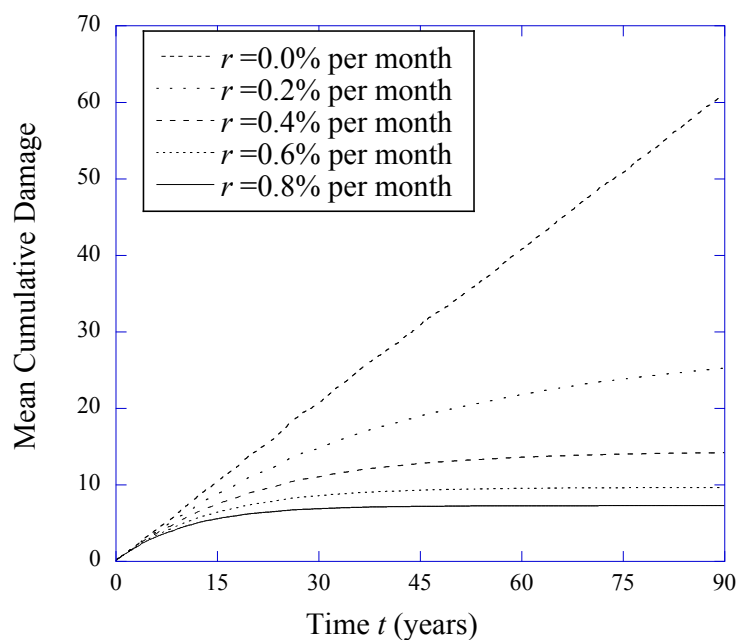

Fig.3. Mean Cumulative Damage for Different Discount Rates $\left(h_{T}=6, T=90\right.$ years)

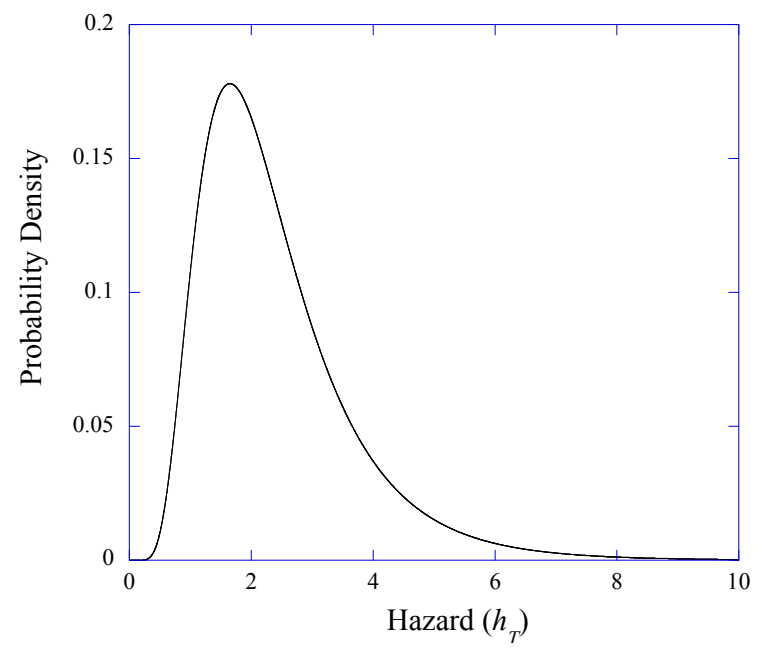

Fig.5. Log-normal distribution of annual hazard occurrence in no climate change scenario

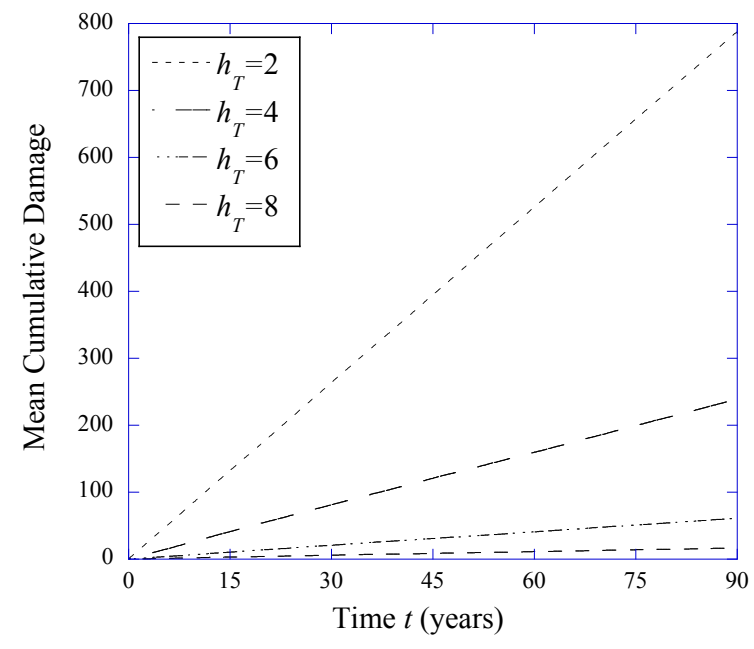

Fig.4. Mean Cumulative Damage for Different Threshold $h_{T}(r=0.0 \%, T=90$ years $)$

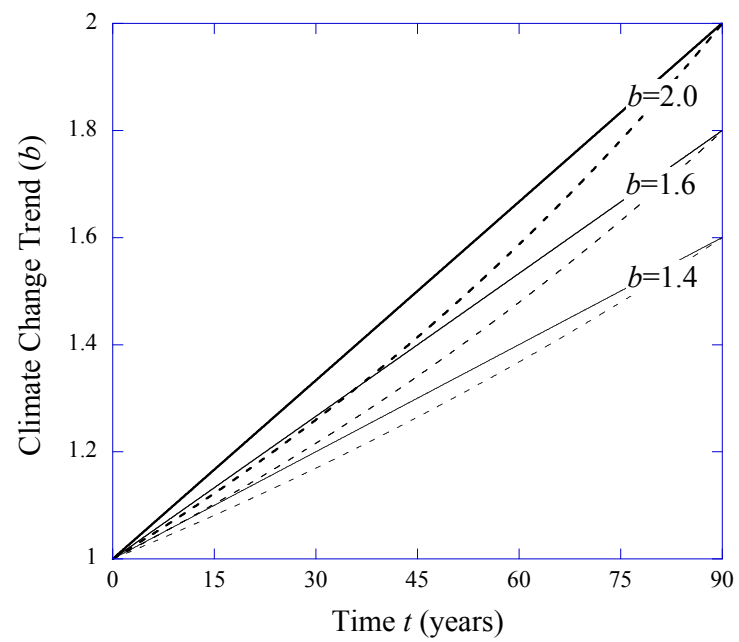

Fig.6. Climate Change Trend for 0 to 90 years, linear (solid line) and nonlinear (dotted line)

damage cost can be minimised if climate change adaptation strategies are adopted earlier, which results in a higher possibility of getting benefits from the strategies adopted.

Followed by this result, the impact of different threshold values is explored. Fig.4 shows the damage under different threshold values for $r=0.0 \%$. If $h_{T}$ is halved, the mean cumulative damage increases four times. If $h_{T}$ is doubled, the mean cumulative damage reduces 90 percent. As a conclusion, the results are very sensitive to threshold $h_{T}$. This is because of the log-normal distribution of annual hazard occurrence as shown in Fig.5, when $h_{T}$ is 2 , the area of damage occurrence is much larger than the area when $h_{T}$ is 4 . The long tail of lognormal distribution is the part where damage occurs when $h_{T}$ exceeds 4 .

\subsection{Climate Change Scenario}

In the climate change scenario, parameter $a$ is set at a constant value 1 and climate change trend $b$ is increasing linearly or non-linearly from 1 to 2 at time $T$ (Fig.6) because climate change is predicted to be more serious in the future. Vulnerability Model \#2 in Fig. 2 is applied herein. The threshold is set to $h_{T}=6$. When the climate change trend is linear, the time-dependent damage is shown in Fig.7, where $b=1$ is no climate change case and $b=2$ represents for the most serious climate change case. Comparing these two cases, the $5^{\text {th }}$ percentile time-dependent cumulative damage increases 368 percent in 90 years. The $95^{\text {th }}$ percentile cumulative damage rises 258 percent and the mean cumulative damage grows 310 percent. When the climate change trend is nonlinear, the time-dependent damage is not significantly affected, so the results will not be explained herein. For the following exploration, all the results come from the linear climate change trend. 


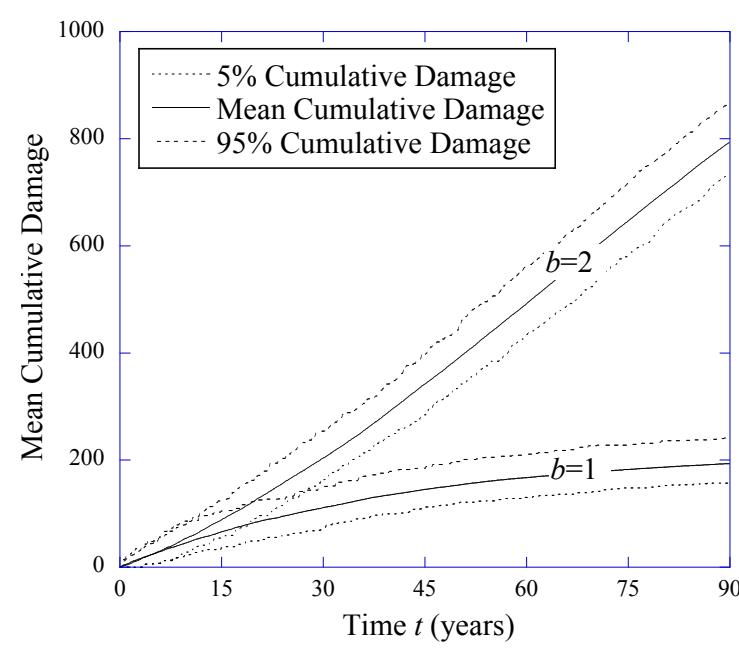

Fig.7. Cumulative Damage for Different Climate Change Trend (Vulnerability Model \#2, $r=0.2 \%$,

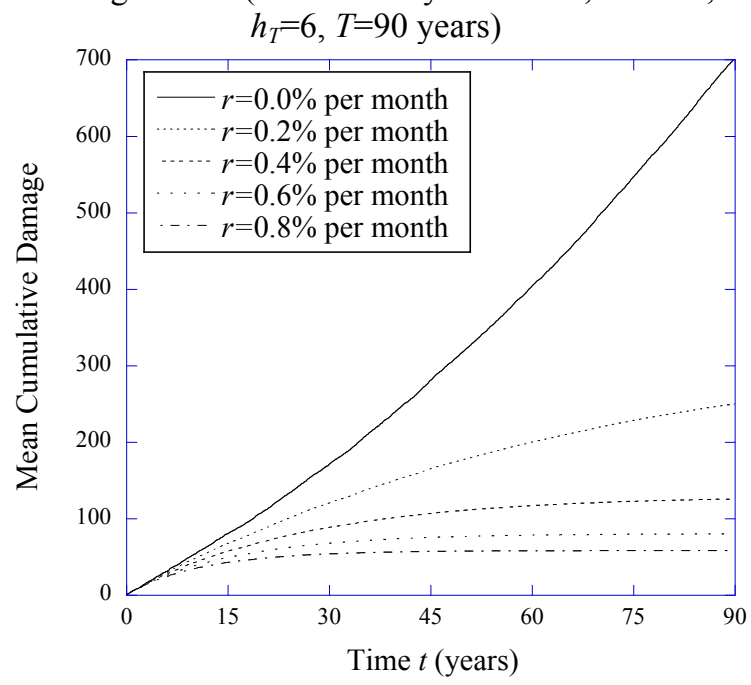

Fig.9. Mean Cumulative Damage for different discount rate (Vulnerability Model $\# 2, h_{T}=6$, $T=90$ years, $b=1.2$ )

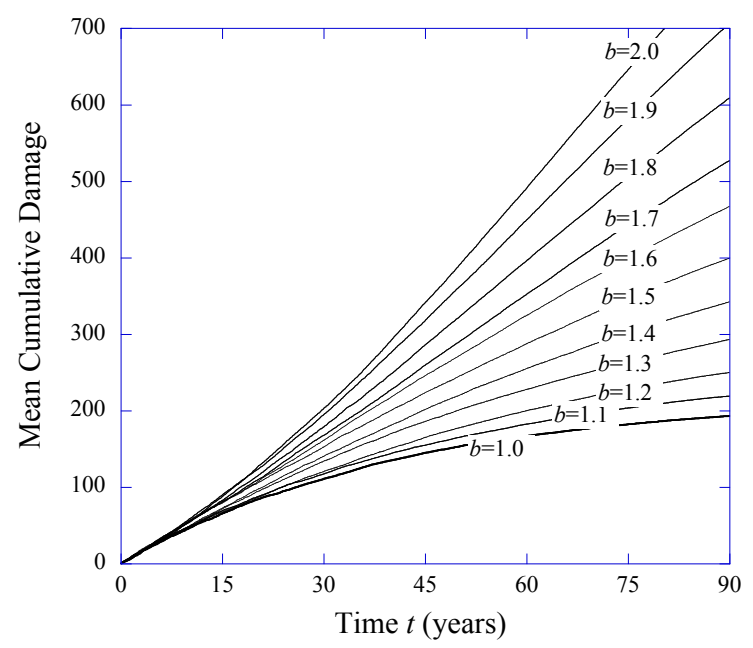

Fig.8. Mean Cumulative Damage for 0 to 90 years (Vulnerability Model \#2, $r=0.2 \%, h_{T}=6, T=90$ years)

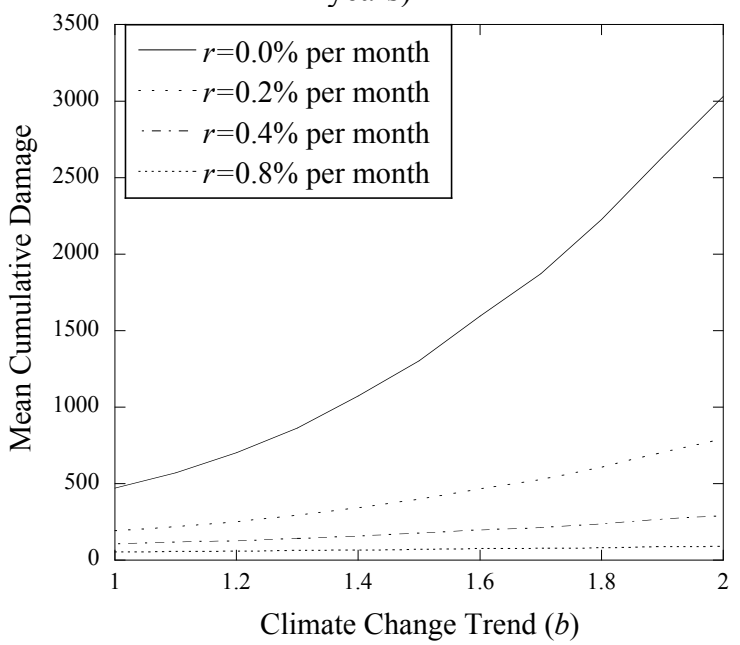

Fig.10. Mean Cumulative Damage at the end of 90 years for Different Discount Rate with Different Climate Change Scenarios $\left(h_{T}=6, T=90\right)$

The time-dependent damage behaviour under different climate change scenarios is shown in Fig.8, the increase rate of time-dependent damage is increasing under more serious climate change scenarios $(b>1.6)$ and decreasing in other climate change scenarios. Fig.9 indicates the effect of discount rate to the time-dependent damage within the same climate change scenario, a high discount rate $(r=0.8 \%)$ will raise the time-dependent damage curve to approach horizontal, hence, the mean cumulative damage doesn't increase in the last few decades. Fig. 10 summarises the effect of discount rate in different climate change scenarios. Without considering the discount rate $(r=0.0 \%)$, the mean cumulative damage has increased almost six fold in 90 years. But with monthly discount rate $r=0.2 \%$, the value only increase to 2.5 times. When the monthly discount rate reaches $0.8 \%$, the mean cumulative damage almost keeps the same within different climate change scenarios because the high discount rate has converted the future damage to a very low present value. In summary, the choice of discount rate is important. High or even moderate rates seem to imply that far-future outcomes doesn't matter much to the present generation. (Ackerman et al. 2006).

In order to enhance the confidence and minimise the uncertainty of the outcomes, the impact of a negative parameter $n$ in the vulnerability function is investigated (Vulnerability Model \#3) and the results are shown in Fig.13. It doesn't change the behaviour of time-dependent damage, but an expected the magnitude of loss is reduced considerably. The Gumbel distribution of climate change hazard is explored to assess the influence of different probability distributions. Comparing Fig.14 with Fig.8, when climate change trend $b$ increases from 1 to 2 , and the mean cumulative damage under the log-normal distribution by the end of year 2100 increases by $310 \%$. When considering the Gumbel distribution, the value increases by $397 \%$. 


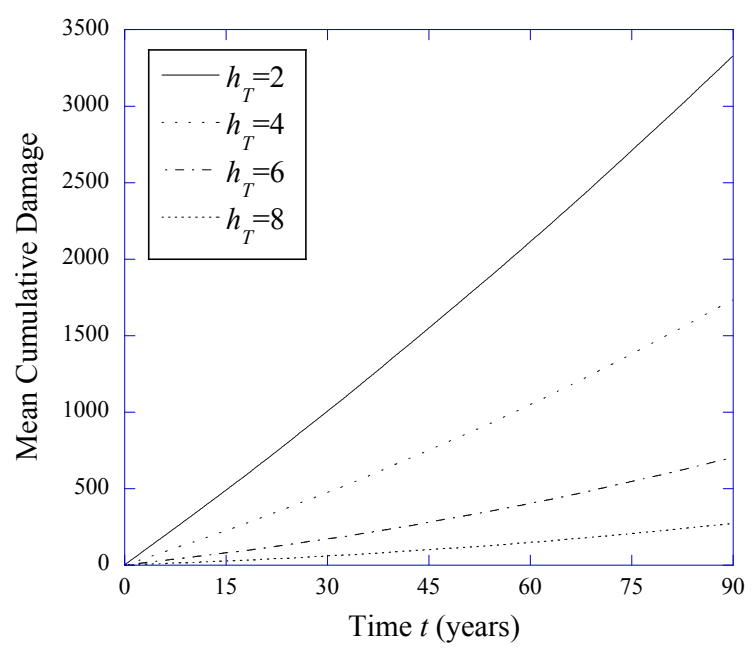

Fig.11. Mean Cumulative Damage for different hazard (Vulnerability Model \#2, $r=0.0 \%$, $T=90$ years, $b=1.2$ )

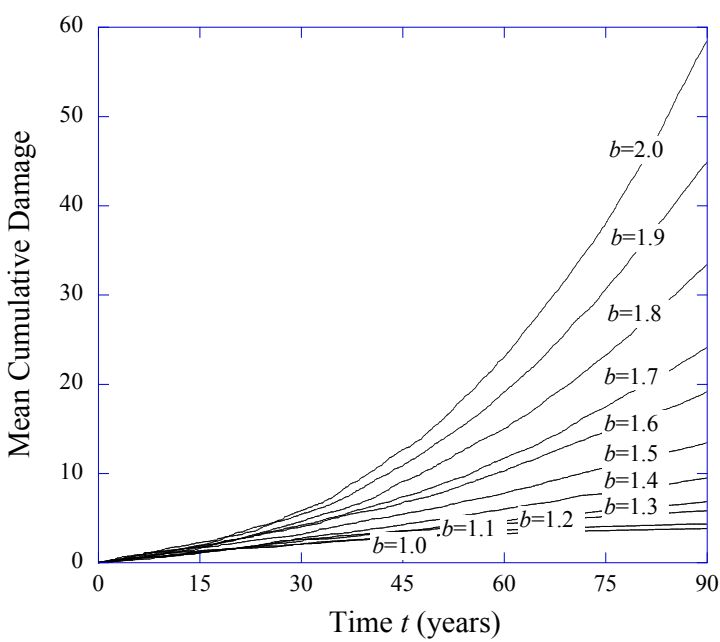

Fig.13. Mean Cumulative Damage (Vulnerability model $\# 3, r=0.2 \%, h_{T}=6, T=90$ years $)$

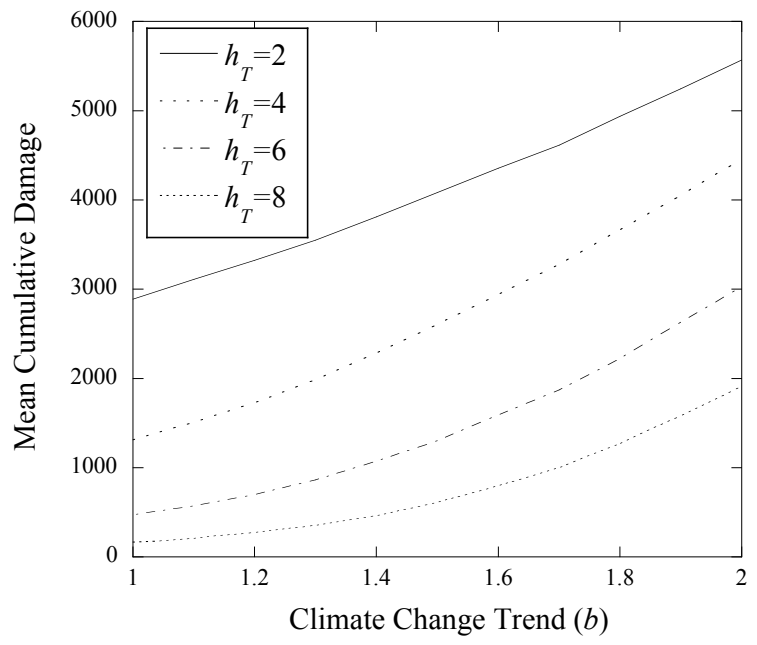

Fig.12. Mean Cumulative Damage for Different Threshold $h_{T}$ with Different Climate Change Trend when $\sigma=0.5(r=0.0 \%, T=90)$

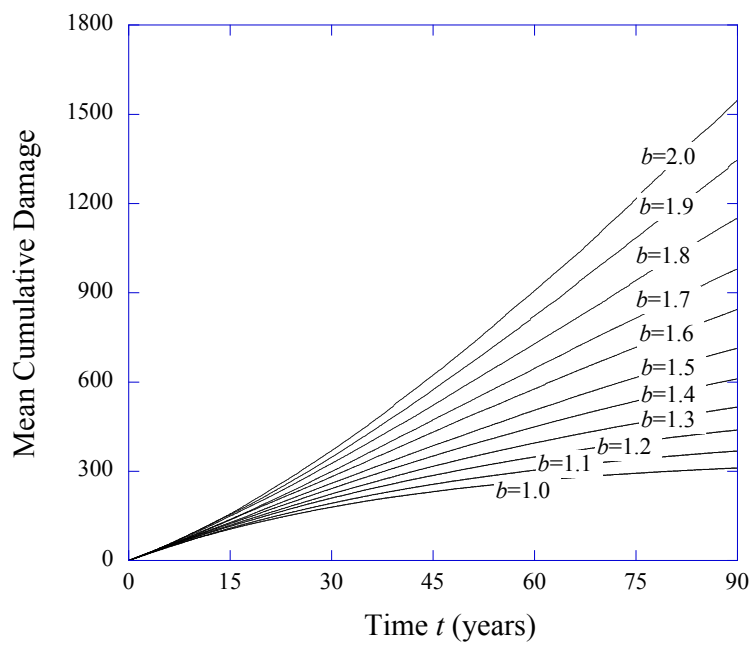

Fig.14. Mean Cumulative Damage with Gumbel Distribution (Vulnerability Model $\# 2, r=0.2 \%, h_{T}=6$, $T=90$ years)

\section{DISCUSSION AND CONCLUSION}

For the same climate change scenario, the time-dependent damage curve is very sensitive to different discount rates. However with the constant discount rate, the time-dependent damage curve will approach horizontal eventually because the present value of far-future outcomes become insignificant when it is multiplied by the discount factor. As indicated by Hepburn (2007), using a constant discount rate is approximately correct over shorter time periods (up to about 30 years), but is increasingly incorrect thereafter, particularly if intergenerational effects are to be considered.

Threshold plays an important role on impacting the time-dependent damage. Generally a higher threshold will result in lower mean cumulative damage as shown in Fig.11. Regarding to Fig.12, with the effect of climate change, a higher damage threshold will result in faster increase rate of damage since the mean cumulative damage increases around ten times when $h_{T}$ is at 8 in 90 years while only increase two times when $h_{T}$ is at 2 within the same time period.

The sensitivity to standard deviation is shown in Fig.15. The mean cumulative damage is higher when the standard deviation is bigger. When the threshold $h_{T}=2$, the increment of $\sigma$ doesn't increase the mean cumulative damage a lot. However, when $h_{T}=8$, a relatively high level, an increasing $\sigma$ brings a significant increase of mean cumulative damage. 


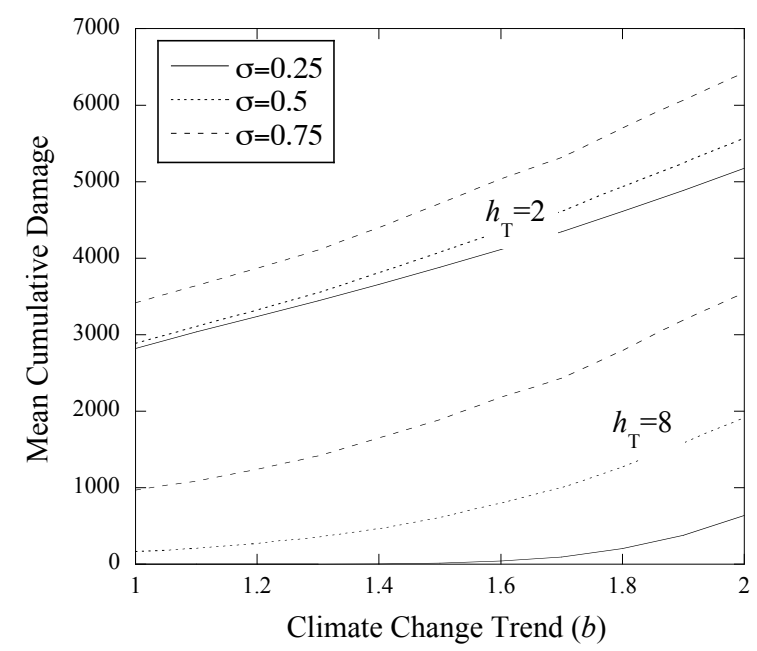

Fig.15. The Mean Cumulative Damage for Different standard deviation $\sigma$ and $h_{T}(r=0.0 \%, T=90$ years $)$

This paper provides a framework for time-dependent damage, which could be applied to real case studies in the future. There are a variety of limitations in both the framework and methodology presented in this paper. Firstly, the factors such as region, season, specific kinds of hazard etc., haven't been considered in the analysis. Secondly, the role of discount rate is explored assuming it is constant with time. According to Stern's review (2006), the discount rate should reduce with time. A single constant discount rate may be unacceptable for dealing with the long-run, global, non-marginal impacts of climate change. So the impacts of discount rate should be explored further. Thirdly, the time-dependent damage unit hasn't been transferred into monetary terms. Lastly, adaptation strategies haven't been modelled in the study.

In conclusion, this paper has explored a general picture of the time-dependent damage using Monte Carlo methods. It focuses on how parameters such as threshold, discount rate, standard deviation and time influence the damage. It was found out that discount rate and climate change trend would affect the rate of increase of damage. Comparing with a low threshold, a high value will contribute to a low damage in the base year, but the damage increases more significantly in the future. Higher standard deviation causes more loss especially when the threshold is at a high level.

\section{References}

Ackerman, F., and Finlayson, I.J. (2006). The economics of inaction on climate change: a sensitivity analysis. Climate Policy, 6(5), 509-526.

Cleugh, H., Smith, MS., and Battaglia, M.(2011) Climate change: science and solutions for Australia, CSIRO Publishing, Collingwood.

Garnaut, R. (2008). The Garnaut Climate Change Review: final report. Department of Climate Change, Commonwealth of Australia, Canberra.

Ginger, J.D., Henderson, D.J., Leitch, C.J., and Boughton, G.N. (2007). Tropical cyclone Larry: Estimation of wind field and assessment of building damage. Australian Journal of Structural Engineering.7(3), 209-224.

Hepburn, C. (2007). Handbook of Sustainable Development, pp109. Edward Elgar publishing Limted, Cheltenham.

Intergovernmental Panel on Climate Change (IPCC). (2007). Fourth Assessment Report of the Intergovernmental Panel in Climate Change. Cambridge University Press, Cambridge, U.K.

Khanduri, A.C., and Morrow, G.C. (2003). Vulnerability of buildings to windstorms and insurance loss estimation. Journal of Wind Engineering and Industrial Aerodynamics,91,455-467.

Li, Y., and Stewart, M.G. (2011). Cyclone damage risks caused by enhanced greenhouse conditions and economic viability of strengthened residential construction. Natural Hazards Review, 12, 9-18.

Pinelli, J.P., Torkian, B.B., Curley, K., Subramanian, C., and Hamid, S. (2009). Cost effectiveness of hurricane mitigation measures for residential buildings. The $11^{\text {th }}$ Americas Conference on Wind Engineering $(A C W E)$, San Juan, Puerto Rico.

Stern, N. (2006). The Economics of Climate Change, pp.36. Cambridge University Press, Cambridge.

Stewart, M.G. (2003). Cyclone damage and temporal changes to building vulnerability and economic risks for residential construction. Journal of Wind Engineering and Industrial Aerodynamics, 91, 671-691. 